\title{
Tool Quality Life during Ball End Milling of Titanium Alloy Based on Tool Wear and Surface Roughness Models
}

\author{
Zemin Zhao ${ }^{1}$, Xianli Liu ${ }^{1, *}$, Caixu Yue ${ }^{1}$, Rongyi Li ${ }^{1}$, Hongyan Zhang ${ }^{1}$ and Steven Liang ${ }^{2}$ \\ 1 School of Mechanical Power Engineering, Harbin University of Science and Technology, Harbin 150000, \\ China; 1610100002@stu.hrbust.edu.cn (Z.Z.); yuecaixu@hrbust.edu.cn (C.Y.); easy198766@126.com (R.L.); \\ 1720110072@stu.hrbust.edu.cn (H.Z.) \\ 2 Manufacturing Institute, Georgia Institute of Technology, Atlanta, GA 30332, USA; \\ steven.liang@me.gatech.edu \\ * Correspondence: xianli.liu@hrbust.edu.cn; Tel.: +86-188-8639-0501
}

Received: 13 April 2020; Accepted: 6 May 2020; Published: 10 May 2020

\begin{abstract}
The prediction and control of milling tool service performance is critical for milling tool design and machining. However, the existing prediction model can hardly quantify tool performance, or precisely describe the relationship between the tool performance and the design or milling parameters. This study redefines the tool lifetime as a function of surface roughness and proposes a new geometric analysis method based on a time-varying wear model. The proposed method can be utilized to evaluate the relationship between tool wear and lifetime. The surface roughness, with respect to tool service performance, is expressed as a time-varying model of the tool and processing parameters. After experimental validation, the influence factors were analyzed through simulation. A generalized method for milling tool design was proposed and successfully applied to a tool performance design case, on a theoretical level. Additionally, the research results prove that basing the tool milling quality life on the surface roughness is extremely feasible and necessary.
\end{abstract}

Keywords: ball-end milling tool; tool life; surface roughness model; milling tool design method

\section{Introduction}

Titanium alloy materials are widely used in the manufacturing of aerospace parts [1], which are gradually becoming larger in volume and more complex. The tools that are generally applied to materials are difficult to machine, thereby resulting in increased tool consumption and burden. Currently, matching the tool performance with processing requirements is very important. If the function or structural design cannot meet the present high specialization requirements, a customized performance design is necessary for the development of milling tools. The realization of a customized performance design is the primary premise in intelligent design; however, there are currently few related studies focused on this. As the most front-end equipment in the manufacturing process, cutting tools are regarded as the tooth of a machine. Thus, the quality of parts is dependent on tool performance, which gradually decreases with tool wear until the surface quality does not meet the processing requirements. Tool wear is a key bridge that connects tool status to the surface quality.

Surface quality is one of the most influential processing requirements, as well as an important indicator, for judging tool performance. Wear of the milling tool during the machining process directly affects surface quality [2]. Surface quality refers to the microscopic unevenness of the machined surface, also known as roughness. The working performance, reliability, and life of the workpiece all depend, to a large extent, on the surface quality of the finished good. To achieve the designed performance, the relationship between the wear and surface quality should be accurately 
established first. In terms of the relation establishment, XianLi Liu and Wei Ji [3-5] proposed and validated a tool shape-performance-application design method. This integrated the constraints relation between geometry, force, heat, and materials, as well as its theories, into design features. By combining with algorithms of programmed tool design platforms, the tool customization design was achieved. However, this is a constraint relationship rather than a certain functional relationship and does not intuitively reflect the relationship between the parameters and performance. In addition, MR Khan [6] used the NURBS curve and the scan surface to generate the geometry of milling tools. By controlling the polygon and scanning the trajectory to control the tool shape, a precise geometric model was established for a class of milling tools. Huang Yong, SY Liang, and KM Li [7,8] successfully constructed a wear rate model with turning tool design parameters by equivalent geometric and physical volumes. TM Teitenberg [9] established a relationship between the tool geometry and the milling force to simulate the circumferential wear. Furthermore, Bouzakis K D and Paraskevopoulou R, et al. [10] created a tool wear predictive mathematical model for milling parts of complicated geometry. Their model used factors on the entry impact duration of the cutting edge as well as a commercial CAM system. The parameters of the developed model were determined based on the experimental results. The abovementioned studies employed different methods to establish a certain functional relationship between the design parameters and the wear or cutting force. However, the wear and milling forces are not a direct performance index or processing requirement in manufacturing. Thus, the relation between the performance and design parameters requires further improvement.

To achieve performance design, a certain functional relationship between the performance and design parameters must be established. In summary, based on the shape and application conditions of the tool, a functional relationship between the wear and design parameters has been constructed [11]. The wear can also greatly impact surface qualities such as the roughness. At present, research on the surface roughness mainly relies on modeling methods, algorithms, experimental methods, and combinations thereof. F.G. Biondani and G. Bissacco [10] provided a method for modeling such interactions, taking into account cutting edge topography, material deformation, and cutting edge trajectory errors. Using this method, a reliable prediction of the surface topography generation in ball end milling was achieved. M.S. Kasim and M.S.A. Hafiza et al. [12] investigated the quality of the Inconel 718 surface during the end milling process. The surface roughness measured in the feed direction was found to be lower than that in the pick direction. K.-D. Bouzakis and P. Aichouh et al. [13] developed a computer-supported milling simulation algorithm referred to as 'ball mill'. This was used to predict the workpiece roughness in multi-axis finishing milling using ball end tools. Based on this algorithm, considering the individual movements of the cutting tool and workpiece due to the milling kinematics, the undeformed chip geometry, cutting force components, tool deflections, and final surface topomorphy expected can be determined. The research results of the above scholars are relatively complete and representative, which have great reference value.

During the machining process, due to the close contact of tool and workpiece material, the materials abrase, adhere to, and diffuse each other, resulting in wear. Abrasive wear occurs during the entire machining process, and the hard particles shed from the tool body form a three-body wear pattern between the tool and the workpiece surface, which has a great negative impact on processing quality. Related research shows that adjusting cutting parameters is an effective improvement method [14]. In addition, improving the lubrication conditions can significantly reduce the milling force and milling temperature $[15,16]$, which is the root cause of wear generation and expansion. Similarly, adding a coating to the tool also has a significant effect of reducing wear [17]. The relationship between wear and machining quality is also complicated, which can be divided into directly and indirectly affects. For example, the tool path affects the tool wear distribution characteristics and vibration characteristics, thereby affecting the machining quality $[18,19]$. For difficult-to-machine materials, the above factors have a more significant impact on wear. These factors significantly affect the tool wear rate and machining quality [20]. However, the machining of the workpiece primarily depends on the geometric creation $[21,22]$. 
The surface roughness $R_{a}$ perpendicular to the feed direction is particularly significant [12]. These factors are closely related to other geometric factors, including the tool wear. This paper focuses on establishing the relationship between the tool wear and workpiece surface roughness with time-varying. As current relevant research results do not fully include time, tool design, and cutting parameters, these models cannot be directly used for the control prediction and tool design in the service performance.

The realization of machining requirements depends on tool performance, and the tool lifetime should be further linked to the corresponding machining requirements and quality. With the progress of time, the overall research trend of surface roughness in academia has gradually shifted from the establishment of analytical models, to the application of simulation software and algorithms. X. Wang and C.X. Feng $[23,24]$ developed an empirical model for the prediction of surface roughness in finish turning. The workpiece material hardness, feed, cutting tool point angle, depth of cut, spindle speed, as well as cutting time were all considered in this model. A nonlinear regression analysis, along with logarithmic data transformation, was applied in the development of the empirical model. A. Mansour and H. Abdalla [25] developed a mathematical model for the surface roughness in terms of the cutting speed, feed rate, and axial depth of cut in end milling (EN32M). The design of the experiments and the response surface methodology were applied to study the effect of these cutting parameters on the surface roughness. In high-speed end milling, these models do not account for the vibration of the spindle system. Ki Yong Lee and Myeong Chang Kang [26] suggested a simulation algorithm and programming method to simulate the machined surface using an acceleration signal in high-speed end milling. Further studies on surface roughness have focused on modeling or algorithmic methods that rely on cutting parameters and signals, such as force or vibration. Throughout the research process, tool design parameters have not been fully considered because scholars mostly use indirect methods, such as the empirical method and response surface method. Additionally, related research on the direct modeling method is insufficient.

Surface roughness, a process quality indicator that is closely related to the tool lifetime for machining needs, should not be considered an isolated design parameter. Instead, surface roughness should be linked to the tool lifetime, as well as the remaining useful life. The existing tool life definition, based on the failure criterion of tool wear $[27,28]$, cannot directly reflect whether the machining quality of a worn tool under different requirements still meets the demand. Moreover, related research on the remaining useful tool lifetime of a ball end mill does not directly identify any relationship between the tool design parameters, cutting parameters, and tool lifetime. Research on tool life modeling has mainly focused on early studies into the subject matter. M. Alauddin and M.A. El Baradie [28] developed mathematical models for the tool life in end milling steel using high-speed steel slot drills under dry conditions. The predictive models were developed in terms of the primary machining variables, such as the cutting speed, feed rate, and axial depth of cut, by response surface methodology. The method construction process mainly relies on response surface method.

As a consumable part of the manufacturing front-end process, a reasonable processing plan of a tool, according to the processing demand and its service performance, will enable sufficient tool performance throughout its whole lifecycle. The ability to utilize the full life expectancy of a tool can undoubtedly significantly reduce production costs and even improve processing quality [28]. Compared with previous studies, this study innovatively relates the time-varying characteristics of tool wear to the quality of the workpiece to represent the time-varying characteristics of tool machining performance. Unified the tool life and machining performance. In addition, the model completely contains important design parameters and operating parameters of the ball end milling tool, so the research of tool service performance can be conducted with the goal of emphasizing additional useful tool design parameters, and the modeling process can provide the basis for determining the design of cutting tools for optimal performance, according to the processing requirements. 


\section{Definition of Tool Milling Quality Life}

\subsection{Surface Roughness and Wear}

Traditionally, tool life is judged according to a generalized standard that does not directly reflect and quantify the relationship between surface quality and wear. Through continuous improvement of the requirements of parts for machining quality, the accuracy of a workpiece with high machining quality is more often inconsistent with the standard of tool blunting. Under different processing requirements, tools meeting the blunt standard may not meet the processing requirements, particularly in finishing. As shown in Figure 1, the relative sizes of $R_{a}$ and wear $V B$ are not fixed until the conditions, such as tools utilized, and the processing method are determined. This directly leads to a mismatch between the maximum surface roughness demanded and the wear allowed by failure criteria.

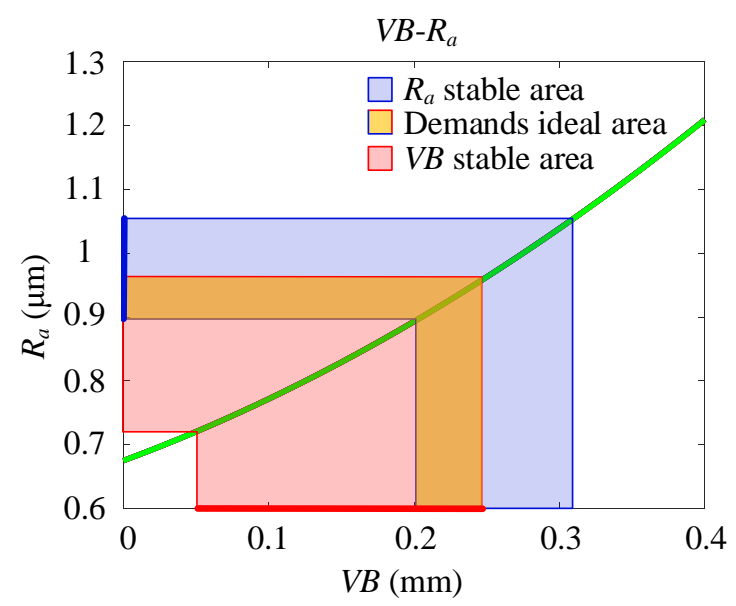

Figure 1. Relationship between wear and surface roughness.

Furthermore, $R_{a}$ and $V B$ are affected by many different factors, and they have different distribution characteristics and different relatively stable region. As shown in Figure 1, since the relationship between $R_{a}$ and $V B$ not strictly linear, stable areas of them are not completely overlapping. In the field of aerospace, the stability of workpiece quality is critical [29]. During processing, the stable areas of $R_{a}$ and $V B$ are expected to overlap as much as possible to ensure processing stable and high quality. However, due to the diversity of processing demands, the overlap area of $R_{a}$ and $V B$ is usually small, and the stable performance area of a tool is not fully and reasonably applied. If the coincident areas of the $R_{a}$ stable areas and the $V B$ stable areas is defined as the ideal demand area, a more reasonable application is clarifying the relationship between $R_{a}$ and $V B$ and maximize the use of stable overlapping areas. Then locating the processing demand in the roughness stable area, as this part coincides with the wear stability. However, tool wear is not the only factor affecting the surface roughness, there are other factors that cause the stability areas of $R_{a}$ and $V B$ to not completely coincide. In addition, the machining requirements are different, tools that do not meet the blunt criteria may not continuously meet machining requirements as the tool wear progresses, under certain processing requirements. The ideal area of $R_{a}$ under the experimental conditions results in $V B$ entering the accelerated wear phase very quickly, while other unsteady regions exhibit a rapid change of $R_{a}$ and $V B$. This behavior is clearly not conducive to the processing stability. So, before establishing a clear relationship between $R_{a}$ and $V B$, it is very necessary to define the tool life based on the surface quality that can characterize the tool performance, which links the tool wear, surface quality, and machining demands together. 


\subsection{Tool Milling Quality Life}

The evaluation of tool lifetime should be based on its lowest machining quality under the fixed working conditions of a working procedure. Compared with the tool wear, requirements on a workpiece can directly correspond to tool lifetime. Integrated parts with a large volume require a more continuous processing time and less processing quality fluctuation. Therefore, the processing tool life and quality are important tool performance indices that should be considered, while surface roughness is the most direct index for characterizing the performance in machining quality. In the normal cutting area without considering built-up edges and chipping, among others, geometry is the main factor contributing to the surface roughness, where the milling residual height directly determines the surface roughness of the milling $[30,31]$.

Here, tool life is defined as the maximum working time for a particular tool without exceeding the minimum machining demand $D_{\min }$ under certain conditions, also known as tool milling quality life, $Q$. It is important to note that $Q$ is defined based on the machining demand rather than tool wear; in this study, the tool wear is considered too ambiguous to connect with the machining quality and machining demands, as well as reflecting the tool processing performance. The $D_{\min }$ in Figure 2 is utilized to form the most basic processing requirements, which can comprise a large scope of requirements. Some of these requirements are minimum quality, minimum processing efficiency, and minimum cutting force, among others, or a combination of them. However, this paper only focuses on studying and discussing the surface roughness with respect to the demand index. It is assumed that the processing order has no significant effect on tool damage, based on the damage accumulation theory [32], and there is no uniform standard for the value of the tool milling quality life. Additionally, tool milling quality life should varies depending on the specific machining requirements, the tool utilized, and the cutting conditions, as shown in Figure 2. In this study, for a certain surface roughness demand $D_{\min }$, different machining conditions result in different tool lifetimes. As shown in Figure 2, the tool milling quality lifetimes, $Q_{1}, Q_{2}$, and $Q_{3}$, also show the ability to maintain consistent quality of the same tool under different processing conditions. When specific machining demands are proposed, the quality life as the link between the machining quality and the tool lifetime can be used to select the tools that meets the machining demands or to determine the machining conditions, otherwise, it can also predict the tool machining quality at any certain processing stage.

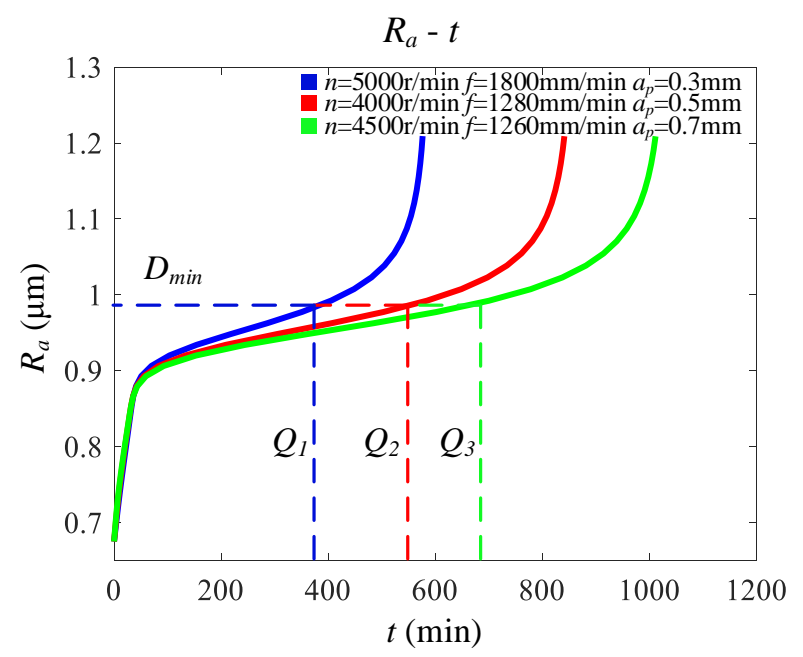

Figure 2. Tool milling quality life under different cutting conditions.

This could be considered a significant practical advantage of this definition over the previous models, as it is capable of reflecting the real-time processing performance of the tool directly, as well as estimating the remaining useful tool life of any tool, regardless of its usage history, with a simple model calculation. Today's aerospace components are larger and more complex than ever, and the 
manufacturing of these components requires machining methods. These components not only require high machining accuracy and consistency, but are often used in harsh environments over an extended period. Clearly, the process planning should be determined mainly by referring to the time-varying characteristics of the processing quality. Consequently, the definition and application of the tool milling quality life is very important.

In particular, Figures 1 and 2 are not hypothetical, but show the actual relationships derived from subsequent modeling, experimentation, and simulation studies. The $R a-V B$ relationship in Figure 1 comes from a combination of the $R_{a}-t$ model and $V B-t$ model, which is verified in Section 4.2 of this paper. Elimination of the time variable $t$ and the $R_{a}-t$ relationship in Figure 2 comes from the model simulation, which was also verified.

\section{Surface Roughness Modeling Based on Residual Height}

\subsection{Surface Roughness without Wear}

Assume that a thin wall convex surface part was machined with a ball end milling tool by one-way row cutting, as shown in Figure 3. The instantaneous curvature along the feed direction is defined as $\rho^{\prime}$ and the curvature orthogonal thereto as $\rho$, as shown in Figure 3a,b. As this assumption is based on machining in a five-axis $\mathrm{CNC}$ machining center, $\rho^{\prime}$ was not introduced in the derivation process and experimental sample design.

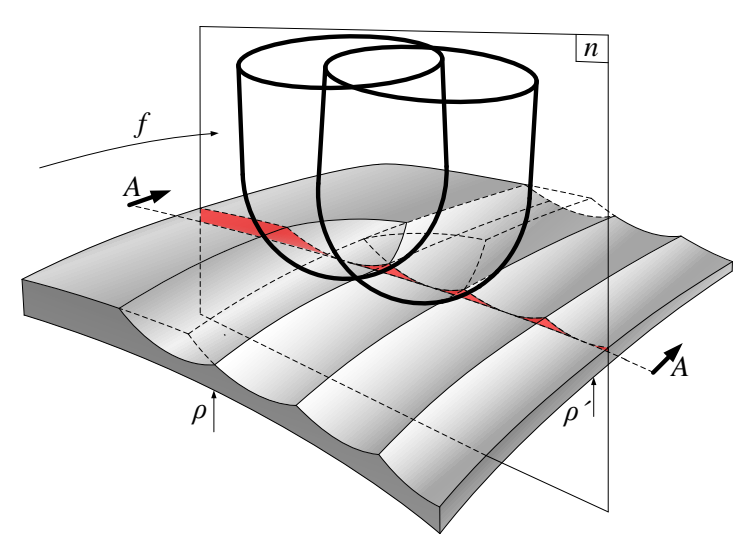

(a) Processing posture description

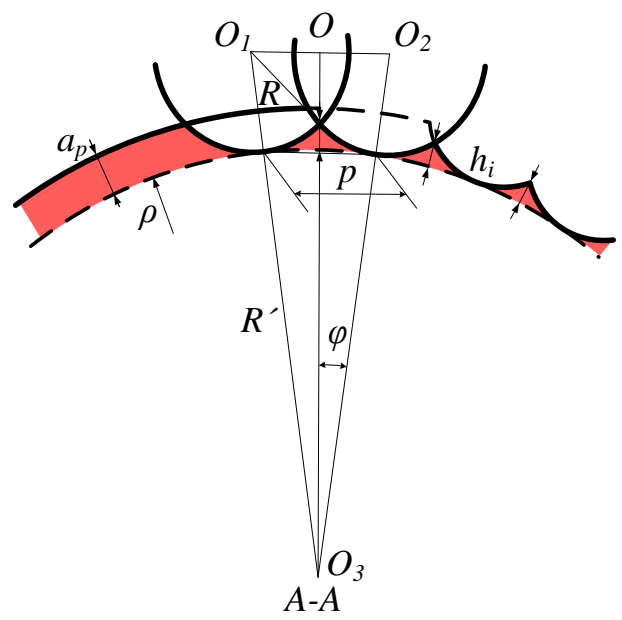

(b) Residual height section

Figure 3. Surface milling residual height diagram.

The milling part is shown in section A-A of Figure $3 a, b, O_{1}$ denotes the center of the ball end milling tool in processing, and $\mathrm{O}_{2}$ denotes the center of the ball end milling tool on the adjacent tool path that has just been milled. The residual height is expressed as Equation (1) due to the change in curvature, and is related to the curvature $\rho$, where $R$ is the radius of the ball end milling and $p$ is the row spacing. Additionally, $h(\theta)$ is the contour height function, as shown in Figure 4. The $h(\theta)$ can be deduced in an analytical form.

$$
h(\theta)=R_{o} \cdot[\cos (\varphi-\theta)-1]+R-\sqrt{R^{2}-\sin ^{2}(\varphi-\theta) \cdot R_{o}^{2}}\left\{\begin{array}{c}
\varphi=\arcsin \frac{\rho \cdot P_{\text {initial }}}{2 \cdot\left(1-\rho \cdot a_{p}\right)} \\
R_{o}=\frac{1}{\rho}\left[1+\rho \cdot\left(R-a_{p}\right)\right]
\end{array}\right.
$$




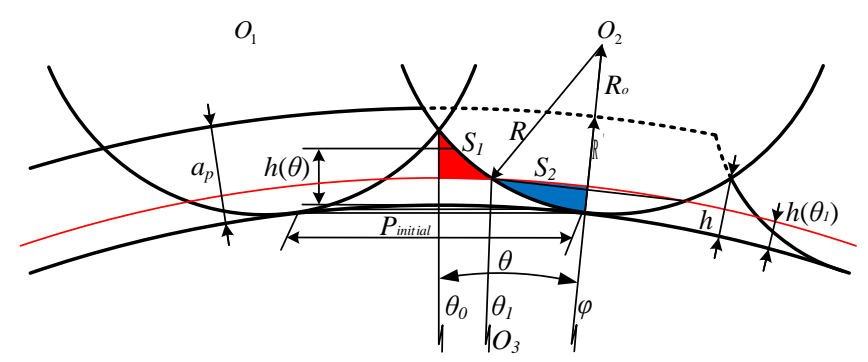

Figure 4. Sketch map of contour height.

Here, $\theta$ is the center angle of the sample length for the integral mean value. To distinguish the subsequent line spacing changes, the initial value of the line spacing is expressed as $P_{\text {initial }}$ and the surface roughness is the average arithmetical deviation of the contour [32]. This can be represented as (2) when applied to surface milling. To calculate the roughness by the average arithmetical deviation of the contour, the midline of the outline can be obtained according to $S_{1}=S_{2}$; at this point, $\theta_{1}$ can be defined as (3). Here, the function $E(\theta)$ can be defined as (4). The definition of $R_{a}$ is given by Equation (5).

$$
\begin{gathered}
R_{a}=\frac{1}{\varphi} \cdot \int_{0}^{\varphi}\left|h(\theta)-h\left(\theta_{1}\right)\right| d \theta \\
\theta_{1}=\varphi-\arctan \left(\frac{\sqrt{4 \cdot E(0)^{2} \cdot R^{2} \cdot \varphi^{2}-\left[\varphi^{2} \cdot\left(R_{o}^{2}-R^{2}\right)+E(0)^{2}\right]^{2}}}{\varphi^{2} \cdot\left(R_{o}^{2}-R^{2}\right)+E(0)^{2}}\right) \\
E(\theta)=R \cdot \text { EllipticE }\left(\sin (\varphi-\theta), \frac{R_{o}}{R}\right)-R_{o} \cdot \sin \varphi \\
R_{a}=\frac{2}{\varphi} \cdot\left[H\left(\theta_{1}\right)-H(0)-\theta_{1} \cdot h\left(\theta_{1}\right)\right]
\end{gathered}
$$

Here, $H(\theta)$ is the integral of $h$ and can be expressed by Equation (6). In addition, all of the integral constants were omitted in the modeling process and will be reflected in the final verification result in the form of amplitude multiple $K$ and translation constant $C$. Surface roughness is a direct demand indicator that can directly express machining quality. Due to the geometric envelope relationship between the ball end milling tool and the curved surface, the machining surface created by the ball end tool without any wear still remains a residual height of material, which leads to $R_{a}$ a non-zero initial value. Since the tool is not worn at this situation, the calculation of the theoretical initial value of $R_{a}$ only needs to substitute the required geometric and kinematic conditions, the milling line spacing $p=0.15 \mathrm{~mm}$ and the sampling length of $R_{a}$, which is replaced by the center angle corresponding to the sampling length $\theta=10^{\circ}$. There is no need to consider the effects of material properties and processing systems. The initial roughness obtained by Substituting the above geometric parameters for Equation (5), and Equation (5) has its initial value of $R_{a}=0.67507 \mu \mathrm{m}$. This value of $R_{a}$ means the initial value cause only by geometric factor of ball end tool and curve surface without tool wear when $t=0$. It is not necessary to consider the influence of material properties and machining system.

$$
H(\theta)=E(\theta)-R_{o} \cdot \sin (\varphi-\theta)-\left(R_{o}-R\right) \cdot \theta
$$

\subsection{Surface Roughness under Flank Wear Condition}

When ball end milling is used to process a titanium alloy, flank wear is the main form of failure [33]. Both the tool lifetime and flank wear are dependent on time. As time increases, the wear can indicate the decline of the tool processing performance. Moreover, the contour of the cutting edge shrinks inward as the wear progresses further. The contour contraction, caused by radial wear, can be equivalent to the increase of the offset, or row spacing, of a milling tool. This can be shown from $\mathrm{O}_{1}$ to $\mathrm{O}_{2}$, or from $P_{\text {initial }}$ to $p$, as in Figure 5. Meanwhile, the variation in the line spacing and corner can be used to replace 
the shrinkage of the tool wear profile to achieve an equal effect, which is the increase in the surface residual height. In this paper, the method of equalizing the shrinkage of the tool profile caused by the wear to the increase of the line spacing or the corner is proposed as the equivalent line spacing or the equivalent corner method. The equivalent angle and row spacing method can be used to establish the relationship between $R_{a}$ and time variation. Here, the equivalent rotation method is used, and the contraction of the contour can be equivalent to the variation of the rotation angle $\Delta \varphi$.

$$
\Delta \varphi=\arctan \left(\frac{R_{M}}{R_{o}-l_{M}}\right)-\arctan \left(\frac{R_{M}-\Delta R}{R_{o}-l_{M}}\right)
$$

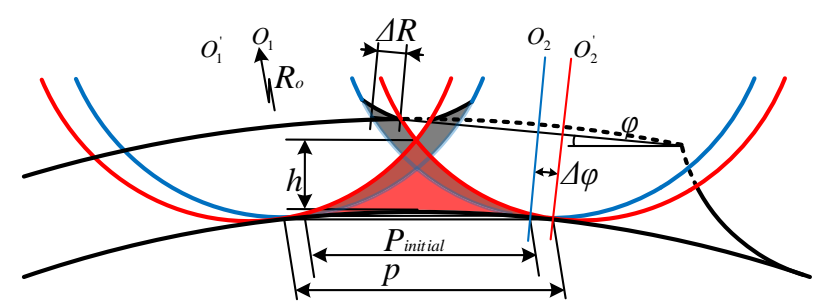

Figure 5. Diagram of the relationship between wear and residual height.

As shown in Figure 6, based on previous studies [11], $\Delta R, l_{M}$, and $R_{M}$ are the radius variation, depth, and truncation radius at the maximum wear point of the ball end milling cutter, respectively. In particular, the maximum wear point was determined by parsing the traditional tool life model built based on tool wear as a position function. The study conclusion shows that the point of minimum tool life is the point of maximum wear of the cutting edge, then, the maximum wear point coordinate $x_{2}$ and the cross-sectional circle radius $R\left(x_{2}\right)$ were derived, the correctness of which has been confirmed. Their expressions are given as follows:

$$
\left\{\begin{aligned}
\Delta R & =\frac{V B(t) \cdot \sin \alpha \cdot \cos \gamma}{\cos (\alpha+\gamma)} \\
l_{M} & =\frac{\left(R-a_{p}\right) \cdot\left[2+\rho \cdot\left(R-a_{p}\right)\right]+\rho \cdot R^{2}}{2 \cdot\left[1+\rho \cdot\left(R-a_{p}\right)\right]} \\
R_{M} & =\sqrt{R^{2}-\left\{\frac{\left(a_{p}-R\right) \cdot\left[2-\rho \cdot\left(a_{p}-R\right)\right]-\rho \cdot R^{2}}{2 \cdot\left[1+\rho \cdot\left(R-a_{p}\right)\right]}\right\}^{2}}
\end{aligned}\right.
$$

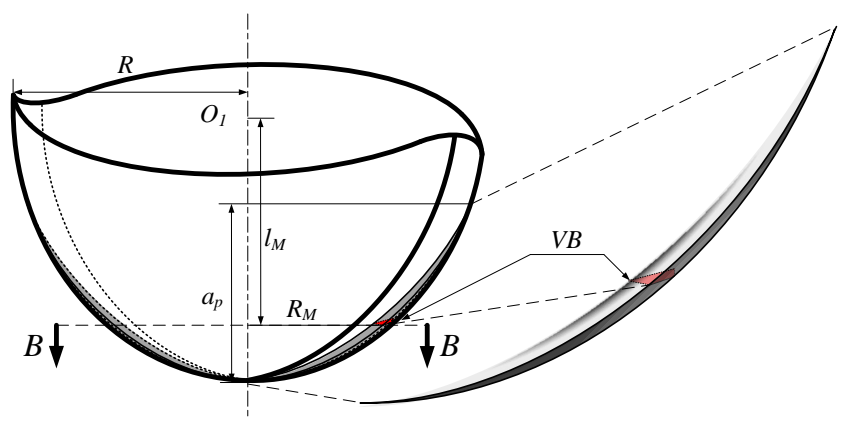

(a) Variable in wear volume schematic

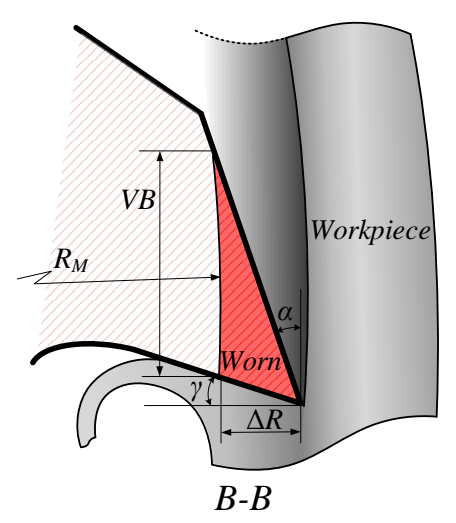

(b) Variable in profile of flank wear width

Figure 6. Variable schematic.

The surface roughness model can be represented by Equation (9), and all $\varphi$ values contained in the substitutions should be replaced by $\omega$ to calculate the surface roughness of the worn ball end milling tool. The angle variable $\Delta \varphi$ is obtained and the angle $\varphi$ can be expressed as (10). The $V B(t)$ 
in $\Delta R$ comes from wear modeling studies [11], as shown in (11), it contains tool design and cutting parameters, as well as machining time variables $t$. In particular, as the inverse hyperbolic function is included in (11), the inverse function of (11) does not exist, but this does not affect the analysis and calculation aided by a computer program.

In Equation (11), the independent variable is $V B$, which represents the tool wear value and as a basic substitute for $R_{a}$ study and $t$ represents machining time. Equation (11) was established based on the principle of linear superposition, which reflects the relationship between $V B$ and $t$ under the influence of three kinds of wear. $K_{1}, K_{2}$, and $K_{3}$ are the comprehensive coefficients of abrasive, adhesive, and diffusion wear, respectively, which are affected by the processing method, environment and material properties of tool and workpiece. Research (11) obtained their values by correcting experimental data. In addition, $a, b, c, d, g, e$ in the substitution formulas $V_{1}$ and $V_{2}$ of (12) are the parameters representing the material properties of the tool and the workpiece, which can be obtained by reference [34,35], $n_{0}$ is a categorical variable, and its value depends on the change rule of tool and workpiece relative hardness with temperature. In addition to geometric and kinematic factors, wear $V B$ and roughness $R_{a}$ are also affected by material properties and processing test environment. Model $V B-t$ (11) mainly relies on the correction and selection of the above two types of parameters to reflect the influence of tool and workpiece material properties on wear, and based on the wear study, $R_{a}-t$ has also introduced the effect of material properties. Through the correction of experimental data, the errors of the machining system and the measuring system are eliminated by the error correction parameters $K_{0}$ and $C_{0}$. The correction and selection of the above parameters are completed in the previous wear study [11], which experimental conditions are the same as in this stud. So, the specific parameter values are directly given in Section 5.1. The experiment and simulation involved cutting stress $\bar{\sigma}=2165 \mathrm{MPa}$ and temperature $T_{0}=475^{\circ} \mathrm{C}$ are selected according to the numerical value of the experiment stable cutting. $V_{c}$ represents the cutting speed that can be determined by calculation and $\alpha$, $\beta, \gamma$, and $R$ in (12) represents the geometric parameters rake angle, helix angle, flank angle and radius of the tool as shown in Figure 6. The surface roughness determined from this model can directly be applied to and describe the service performance of the tool. Additionally, the performance attenuation law of the tool during service can be predicted with this model and contributes to the control of the tool service performance.

$$
\begin{gathered}
R_{a}=\frac{K}{\omega} \cdot\left[H\left(\theta_{1}\right)-H(0)-\theta_{1} \cdot h\left(\theta_{1}\right)\right]+C \\
\omega=\varphi+\Delta \varphi \\
t=K_{0} \cdot\left(\frac{2 \cdot V_{2}^{2} \cdot \ln \left(V_{1} \cdot \sqrt{V B}+V_{2}\right)}{P \cdot\left[R_{M} \cdot V_{1}^{2}-A \cdot V_{2}^{2}\right] \cdot V_{1}}-\frac{R\left(x_{2}\right) \cdot V_{1} \cdot \ln \left[R_{M}-A \cdot V B\right]}{P \cdot\left[R_{M} \cdot V_{1}^{2}-A \cdot V_{2}^{2}\right] \cdot A}-\frac{2 \cdot R_{M} \cdot V_{2} \cdot \arctan h\left(\sqrt{\frac{A \cdot V B}{R_{M}}}\right)}{P \cdot\left[R_{M} \cdot V_{1}^{2}-A \cdot V_{2}^{2}\right] \cdot \sqrt{R_{M} \cdot A}}\right)+C_{0}
\end{gathered}
$$

In this research, $V B$ represents the maximum wear width of the flank wear band, which changes as the milling depth and the part shape change. $\alpha$ is the flank angle, $\gamma$ is the rake angle, $a_{p}$ is the milling thickness, $\beta$ is the helix angle, and $V_{c}$ is the integral median of the linear velocity on the cutting edge involved in milling. $V_{c}$ in (11) is only used for the average temperature estimation in the tool-workpiece contact area of the diffusion wear process as the temperature distribution law on the cutting edge is not the focus of this research. Taking the integral median of the velocity distribution to represent $V_{c}$ based on the integral mean value theorem is a necessary and effective way to reduce the difficulty of 
subsequent integral calculation within the correctness and precision. and $V_{1}, V_{2}$, and $A$ are given by the following equations.

$$
\left\{\begin{array}{l}
V_{1}=\frac{K_{1} \cdot \bar{\sigma}}{\left(a-b \cdot T_{0}\right)^{n_{0}+1} \cdot\left[c \cdot \exp \left(d \cdot\left(273+T_{0}\right)\right)\right]^{n_{0}}}+\frac{K_{2} \cdot \bar{\sigma}}{\exp \left(\frac{e}{273+T_{0}}\right)} \\
V_{2}=\frac{K_{3}}{\sqrt{V_{C} \cdot \exp \left(\frac{8}{273+T_{0}}\right)}} \\
A=\frac{\sin \alpha \cdot \cos \gamma}{\cos (\alpha+\gamma)} \\
B=1-\frac{a_{p}}{R} \\
C=\frac{\pi}{180 \cdot \tan \beta} \\
P=\frac{3 \cdot \tan \beta \cdot \cos (\alpha+\gamma) \cdot V_{C}}{\sin \alpha \cdot \cos \gamma \cdot R} \cdot\left[C \cdot \ln \left(\frac{B-\sqrt{B^{2}+2 \cdot C^{2}}}{1-\sqrt{1+2 \cdot C^{2}}}\right)-\frac{1}{C} \cdot\left(B \cdot \sqrt{B^{2}+2 \cdot C^{2}}-\sqrt{1+2 \cdot C^{2}}\right)\right]
\end{array}\right.
$$

In this study, the average deviation of the contour arithmetic was calculated based on the residual height to represent the surface roughness between passes. Obviously, the roughness between passes is more affected by tool wear than the roughness along the feed. Thus, revealing the influence of tool wear on the surface quality was attempted from a more macroscopic perspective in this research.

\section{Experiment and Verification}

\subsection{Experiment Preparation}

Twenty two-blade ball end milling tools were involved in the experiment, and the spares are shown in Figure 7 with 10-mm diameter, $5^{\circ}$ rake angle, $12^{\circ}$ flank angle, and $50^{\circ}$ helix angle. All of them were tested by a Zoller tool testing instrument. The testing process is shown in Figure 8.
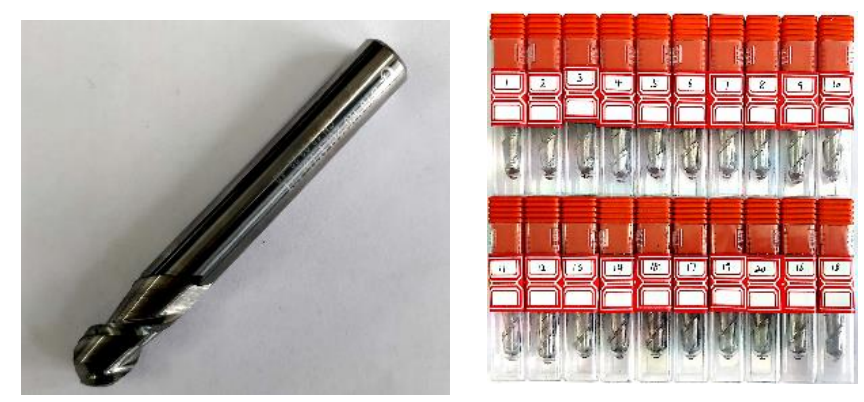

Figure 7. Experimental and spare tools.

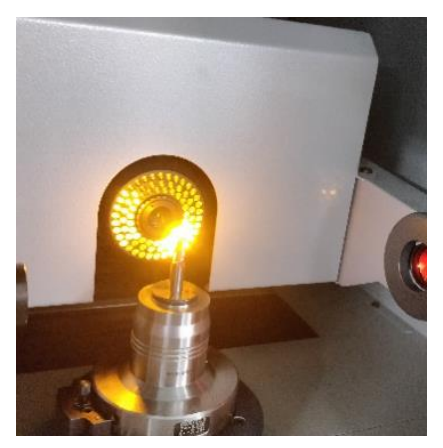

Figure 8. Tool testing on Zoller.

During the tests, the minimum $\left(R_{\min }\right)$ and maximum $\left(R_{\max }\right)$ dimensions of the radius and its standard deviation $S$, the center offset of the edge tip $\delta$, rake angle $\gamma$, axial rake angle $\gamma_{a}$, first flank angle $\alpha$, and helix angle $\beta$ were measured and calculated. The Kendall's coefficient of concordance test results from the SPSS are shown in Table 1. 
Table 1. Verification statistics of tools.

\begin{tabular}{cc}
\hline $\boldsymbol{N}$ & $\mathbf{2 0}$ \\
\hline Kendall's W identification coefficient & 0.961 \\
Asymptotic significance & $0<0.05$ \\
\hline
\end{tabular}

The asymptotic significance is less than 0.05 , making the samples highly consistent. A consistency of up to 0.961 and the Chi-square coefficient shows that the samples were independent of each other. The hardness of the TC4 titanium alloy blank was 30 HRC. In order to cooperate with the experiment to study and verify the relationship between wear and surface quality, the workpiece is planned as multiple segmented surfaces. Besides, the segmented surfaces are set to be inclined at a certain angle to avoid vertex milling and to replace the tool axis inclination angle, so the experiment can be simply conducted on a 3-axis VDL-1000E machine, the detail geometric parameters are shown in Figure 9. In particular, because this study did not focus on the impact of the tool axis inclination angle on the surface quality, the inclination values of different groups of segmented surfaces were specially set so that the cutting edge participates approximately in the same range. During the experimental preparation, the curved surface was produced by wire cutting with cutting fluid. During processing, the part was machined without cutting fluid and at the ambient temperature of $15^{\circ} \mathrm{C}$, as shown in Figure 10 . Furthermore, the flank wear was measured using the ultra-depth of field of the microscope VHX-5000.

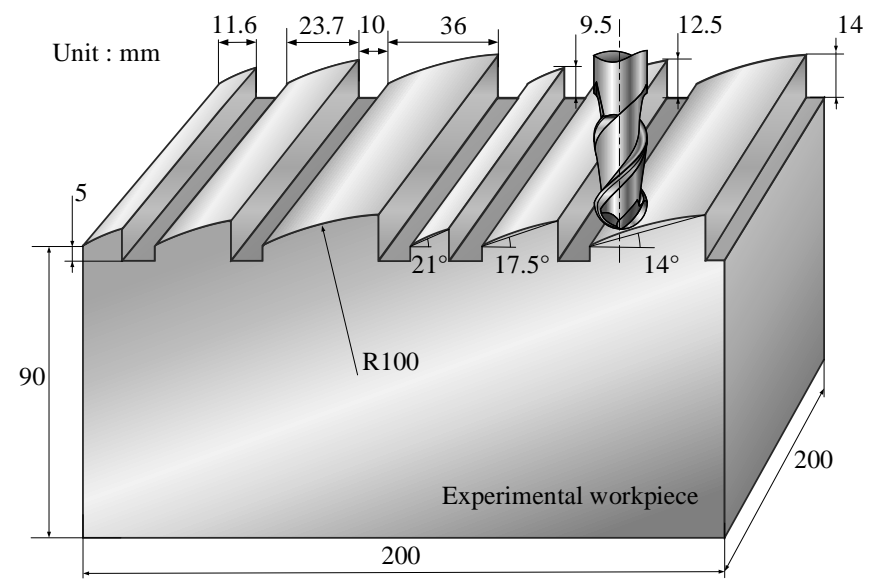

Figure 9. The workpiece geometry.

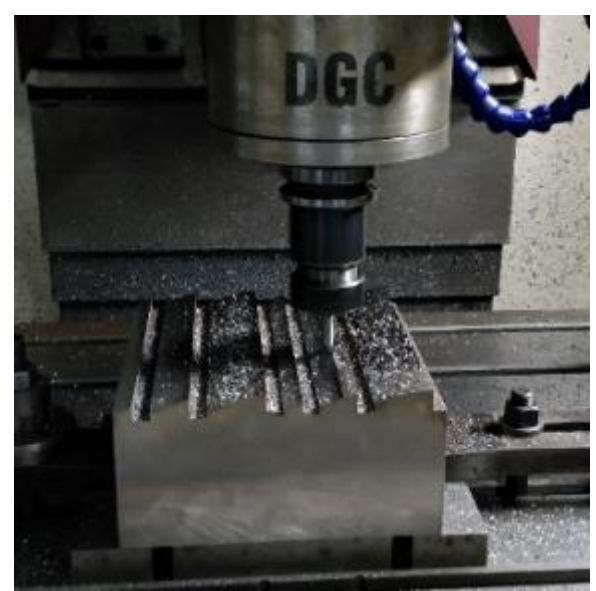

Figure 10. Part surface machining.

In this paper, the wear volume was not measured. Instead, the projection width of the maximum wear, as well as the projection length of the maximum wear point from the milling ball apex were 
measured with the tool tilted at an angle. For accurate observation and measurement, the tool axis was adjusted to an angle of $30^{\circ}$ from the vertical, while maintaining the base plane that crosses the maximum wear point vertical to the horizontal plane, as shown in Figure 11. Specifically, the surface of this experiment was divided into multiple segments, and its curvature was set to 0.01 during the experimental design phase. This is a comprehensive design result that also takes the subsequent research into consideration.
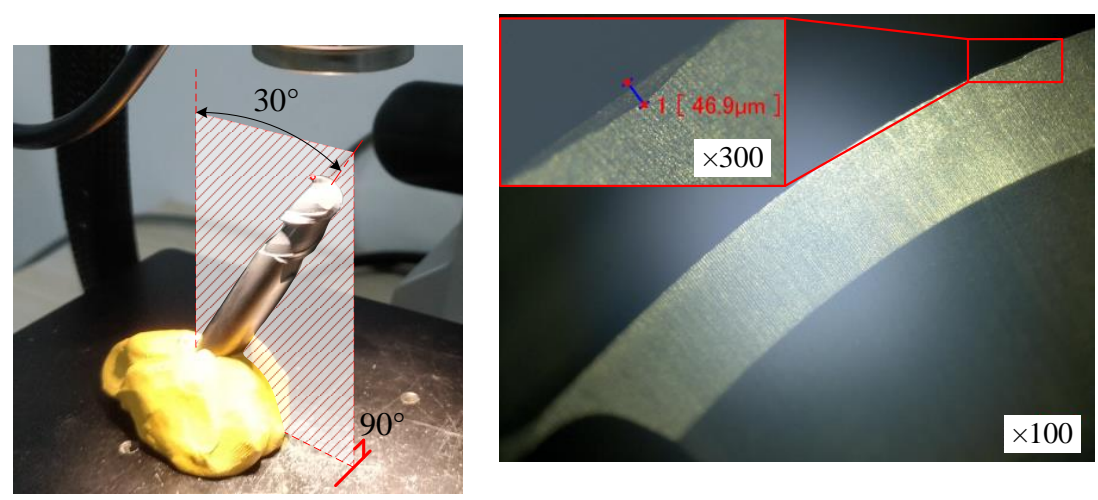

Figure 11. Wear measurement method and result.

\subsection{Model Verification}

The experimental program was a combination of $\mathrm{L}_{9}\left(3^{4}\right)$ orthogonal test, as well as a supplementary experiment, as shown in Table 2. Supplementary experiments 4, 5, 6, 6a, 6b, 8, 9, 10, 10a, 10b, 15, 16, 17, $17 \mathrm{a}$, and $17 \mathrm{~b}$ were placed behind 3,7 , and 14 respectively with the same milling parameters to 3,7 , and 14. The orthogonal test and supplementary experiment based on the test were arranged to provide orthogonal data for the statistical analysis and verification. As shown in Table 2, the milling width was $a_{e}=0.15 \mathrm{~mm}$ and the milling length unit was $L_{u}=16,588.5 \mathrm{~mm}$. $L_{u}$ is the minimum length at which the tool displays significant measurable flank wear under the minimum cutting parameters. During the experimental trial cut phase, as shown in Figure 12, the smallest surface contained a total unit milling length $L_{u}$ under constant $a_{e}$. Additionally, the entire surface was divided to facilitate the study of wear and surface roughness accumulation. The milling sequence was also disrupted for grouping of milling lengths, as well as avoiding systematic errors to some extent.

Table 2. Experimental program.

\begin{tabular}{cccccc}
\hline $\mathrm{G}$ & Tool Code & $n(\mathbf{r} / \mathbf{m i n})$ & $a_{\boldsymbol{p}}(\mathbf{m m})$ & $f_{z}(\mathbf{m m})$ & $\boldsymbol{L}(\mathbf{m m})$ \\
\hline 3 & 5 & 5000 & 0.3 & 0.18 & $3 \mathrm{~L}_{\mathrm{u}}$ \\
4 & 5 & 5000 & 0.3 & 0.18 & $6 \mathrm{~L}_{\mathrm{u}}$ \\
5 & 5 & 5000 & 0.3 & 0.18 & $12 \mathrm{~L}_{\mathrm{u}}$ \\
6 & 5 & 5000 & 0.3 & 0.18 & $24 \mathrm{~L}_{\mathrm{u}}$ \\
$6 \mathrm{a}$ & 5 & 5000 & 0.3 & 0.18 & $36 \mathrm{~L}_{\mathrm{u}}$ \\
$6 \mathrm{~b}$ & 5 & 5000 & 0.3 & 0.18 & $48 \mathrm{~L}_{\mathrm{u}}$ \\
7 & 7 & 4000 & 0.5 & 0.16 & $3 \mathrm{~L}_{\mathrm{u}}$ \\
8 & 7 & 4000 & 0.5 & 0.16 & $6 \mathrm{~L}_{\mathrm{u}}$ \\
9 & 7 & 4000 & 0.5 & 0.16 & $12 \mathrm{~L}_{\mathrm{u}}$ \\
10 & 7 & 4000 & 0.5 & 0.16 & $24 \mathrm{~L}_{\mathrm{u}}$ \\
$10 \mathrm{a}$ & 7 & 4000 & 0.5 & 0.16 & $36 \mathrm{~L}_{\mathrm{u}}$ \\
$10 \mathrm{~b}$ & 7 & 4000 & 0.5 & 0.16 & $48 \mathrm{~L}_{\mathrm{u}}$ \\
14 & 12 & 4500 & 0.7 & 0.14 & $3 \mathrm{~L}_{\mathrm{u}}$ \\
15 & 12 & 4500 & 0.7 & 0.14 & $6 \mathrm{~L}_{\mathrm{u}}$ \\
16 & 12 & 4500 & 0.7 & 0.14 & $12 \mathrm{~L}_{\mathrm{u}}$ \\
17 & 12 & 4500 & 0.7 & 0.14 & $24 \mathrm{~L}_{\mathrm{u}}$ \\
$17 \mathrm{a}$ & 12 & 4500 & 0.7 & 0.14 & $36 \mathrm{~L}_{\mathrm{u}}$ \\
$17 \mathrm{~b}$ & 12 & 4500 & 0.7 & 0.14 & $48 \mathrm{~L}_{\mathrm{u}}$ \\
\hline
\end{tabular}




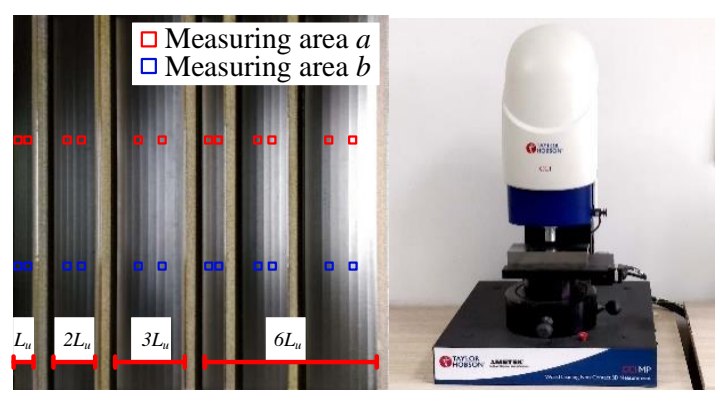

Figure 12. Measuring surface roughness.

The surface roughness of the test piece was detected by Taylor Hobson. A CCI white light interferometer and the measurement position and area are shown in Figure 12. As shown in Figure 10, the surface was divided into multiple segments, and the measurement points were located at $1 / 3$ and $2 / 3$ of each surface. For the comprehensiveness and accuracy of the $R_{a}$ measurement, areas $a$ and $b$ were set in one measurement, and each of them respectively contained a pair of affiliated measurement areas for taking averages [36]. Finally, each sub-surface's roughness is represented by the average of areas $a$ and $b$. To measure the wear, the total time for the tool to travel over a certain surface needs to be recorded. Thus, a new tool must be used for each group of experiments. After milling, the wear of the measurement position was estimated by the final wear of this group, as well as the time recorded. Normal wear is a slow process, and previous trial milling experiments have proven the feasibility.

As shown in Figure 13, with the exception of a few obviously inaccurate measurement points, the values and distribution of the experimental values, as well as the predicted curves, are consistent. As the prediction model ignored some undesirable cutting phenomena, such as the built-up edge and excessive vibration, the experimental values are generally larger than the predicted values. As time progresses, the tool wear gradually increases, and this error will be amplified.

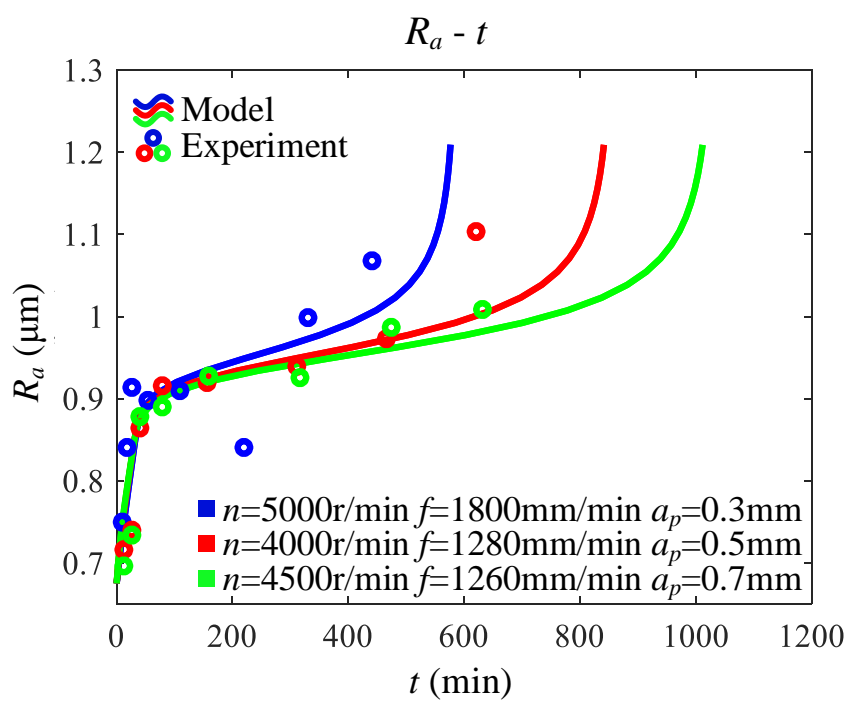

Figure 13. Value comparison of experimental and model data.

Because some influencing factors were simplified or set as constant during modeling, the parameters were divided into two main categories. The first is the model coefficients obtained by reference to the manual and the literature, such as $a, b, \mathrm{c}$, and $d$ in abrasive wear, $e$ in adhesive wear, and $g$ in the diffusion wear shown by (12). The second category is the parameters corrected by conducting research experiments, such as, $K, C$ in (9), $K_{0}, C_{0}$ in (11) and $K_{1}, K_{2}$, and $K_{3}$ in (12). They are both parameters that characterize the materials of the tool and workpiece during processing, but, in fact, they all change with the processing rather than remain constant. The influence of these 
factors expands due to the accumulation of wear. Consequently, this leads to the experiment entering the accelerated wear period earlier than the model.

The systematic error removed measurement data that was compared with the model predicted data corresponding to the same time by SPSS software. The analysis results based on Kendall's W consistency test showed that the value of the asymptotic significance is less than 0.05 , and the null hypothesis was accepted. The model prediction data are consistent with the experimental data, and the consistency is as high as 0.897 . Even if a few points with obvious deviations are included, the model predicts experimental values that are highly consistent in numerical value and distribution, as shown in Table 3.

Table 3. Verification statistics of model.

\begin{tabular}{cc}
\hline $\boldsymbol{N}$ & $\mathbf{2}$ \\
\hline Kendall's W identification coefficient & 0.897 \\
Asymptotic significance & $0.011<0.05$ \\
\hline
\end{tabular}

These data were repeatedly measured and checked during the test, and the results were almost identical. The research value of the deviation points could not be determined during the experiment, so the originality of the measured data has been retained to the greatest extent. Thus far, the correctness of the model was verified by experiments. Through the error of the verification process, the above model achieves a parameter analysis of the surface roughness and tool life. For the tool performance design, the model provides quantitative and qualitative simulation analyses. Thus, the influence of the tool design parameters and cutting parameters on the tool performance can be directly derived.

The processing method in this study has been determined as dry cutting. However, there are still many physical or chemical factors in the actual machining process that significantly influence $R_{a}$, such as the milling force, milling heat, vibration of the system, milling path, differences in the surface integrity caused by material property change during machining $[37,38]$. The effects of the milling forces, milling heat, and part of the material properties are expressed in analytical form in the wear study phase in Equation (12), but the modeling process cannot fully involve all the factors. Although other factors, such as vibration and material property change, are not explicitly expressed in analytical form, the model can achieve sufficient accuracy because the factors not expressed in the model are still implicitly included in the coefficients, such as $K$ and $C$ in Equation (9), which were corrected from real experimental data. Therefore, they contain all the physical or chemical factors that the actual processing should. This is why the general modeling method can maintain an acceptable accuracy under ideal conditions.

\section{Model Simulation and Discussion}

\subsection{Derivation of $R_{a}-V B$ Relationship}

After the experimental verification of $R_{a}-t$ model (9), Appling the same conditions of the experimental, numerical simulation discussions can be conducted based on both $R_{a}-t$ model (9) and the $V B-t$ model (11) verified in previous studies. The detailed simulation input parameters are shown in Table 4. The tool and workpiece material characteristic parameters $T \& W P$, comprehensive wear coefficients $C W C$, and the wear model error coefficients WEC applied in $V B-t$ model (11) all come from wear study [11]. For the simulation discussion based on both VB- $t$ model and Ra-t model, the tool geometric parameters TGP used in this experiment and simulation are also consistent with the wear study. The roughness error coefficients REC are corrected by the experiment in Section 4 of this study. Specifically, since the finishing temperature of the titanium alloy in this experiment is lower than $600{ }^{\circ} \mathrm{C}$, the $n_{0}$ in (12) should be set as zero [34,35], which makes $T \& W P c$ and $d$ in $V_{1}$ of (12) are meaningless in this model, so $b$ and $c$ are not selected by reference. 
Table 4. Simulation input parameters.

\begin{tabular}{ccccc}
\hline TGP & T\&WP & CWC & WEC & REC \\
\hline$\gamma=5^{\circ}$ & $a=15255$ & $K_{1}=9.838 \times 10^{-10}$ & $K=40,923$ & $K_{0}=2000$ \\
$\alpha=12^{\circ}$ & $b=1.6$ & $K_{2}=6.647 \times 10^{-10}$ & $C=18.13$ & $C_{0}=0.53$ \\
$\beta=50^{\circ}$ & $e=23,054$ & $K_{3}=2.923 \times 10^{-6}$ & & \\
$R=5 \mathrm{~mm}$ & $g=3.62 \times 10^{-4}$ & & & \\
\hline
\end{tabular}

In addition, the simulation adopts the same three machining conditions as the orthogonal experiment. The above contents are used as the input parameters and condition employed of model (9), (11) and (12), so that the numerical simulation can be realized based on MATLAB software. As shown in Figure 14 , the $V B-R_{a}-t$ three-dimensional curve can be generated by combining $R_{a}-t$ model and $V B-t$ model. By projecting the three-dimensional curve on the $t-O-R_{a}$ surface, the relationship of $R_{a}-t$ can be obtained, which is consistent with the Figures 2 and 13, and by projecting the three-dimensional curve on $t-O-V B$ surface, the relationship of $V B-t$ can be obtained. Furthermore, when model $V B-t$ and model $R_{a}-t$ are merged without $t$ variable and the three-dimensional curve is projected on the $V B-O-R_{a}$ surface, the relationship curve of $R_{a}-V B$ can be generated, as shown in Figure 14, which is consistent with the Figure 1.

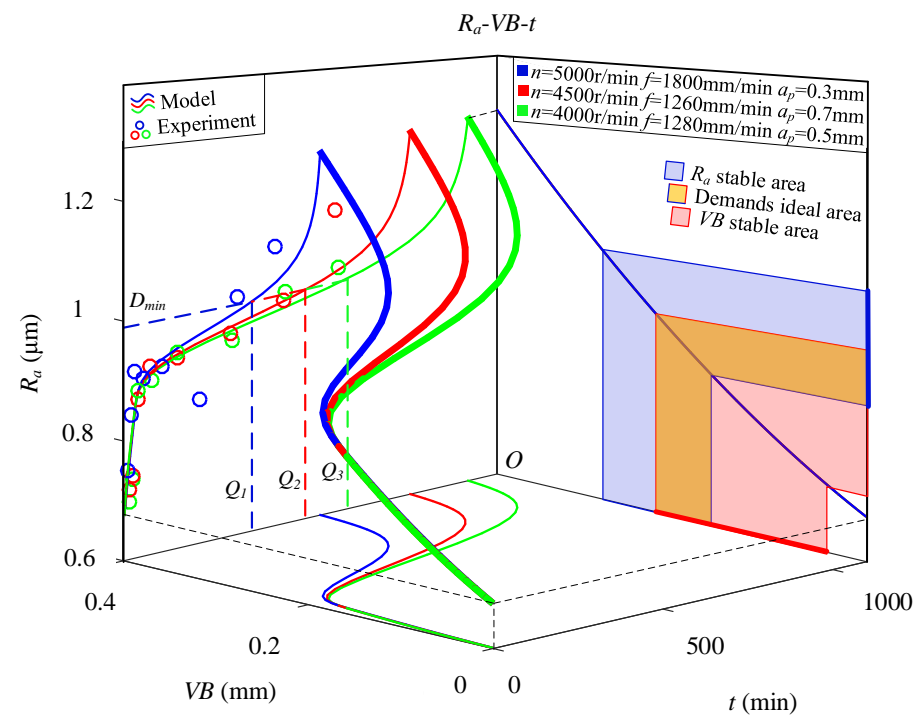

Figure 14. Derivation process of $R_{a}-V B$ relationship.

As shown in Figure 14, the distribution characteristics of $R_{a}$ and $V B$ are very similar but different. The main difference is that the starting points of $R_{a}$ and $V B$ are different, due to the geometric envelope relationship between the ball end milling tool and the curved surface, the machining surface created by the ball end tool without any wear still remains a residual height of material, which leads to $R_{a}$ a non-zero initial value. In addition, the relationship of $R_{a}$ and $V B$ are not strictly linear, which is the key reason makes the relatively stable regions of $V B$ and $R_{a}$ do not coincide as described in Figure 1.

\subsection{Analysis of Main Influencing Factors}

The simulation, based on Equation (9), was performed as shown in Figure 15a-h, which shows the influence of the tool design parameters and milling parameters on $R_{a}$. Any unnecessary cross-factor analysis was omitted, and the intra-group interaction analysis of the main factors affecting $R_{a}$ was completed, as shown in Figure 15a-e. Additionally, (a)-(c) represent the cross-factor analysis of the tool design parameters, and (d) and (e) represent the cross-factor analysis of the milling parameters. In particular, the variables and dependent variables displayed on the axis were the objects in the analysis, and the other factors not involved in the images were set as fixed values for comparison 
purposes. For example, in Figure 15c, the independent variables analyzed were $\beta$ and $\gamma$, and the dependent variable was $R_{a}$, then, $\beta$ and $\gamma$ were the variables within a certain range, and $R_{a}$ changed accordingly, while the parameters not involved in Figure 15c were set as constant, such as the tool parameters, radius $R$, number of teeth $Z$, flank angle $\alpha$, machining parameters, feed $f$, milling depth $a_{p}$, speed, $n$, line spacing, $p$, those of the workpiece being machined, and curvature $\rho$. The dependent variable generated a surface with the change of the two independent variables, and the surface synthesis reflects the interaction of the two independent variables on the same dependent variable.

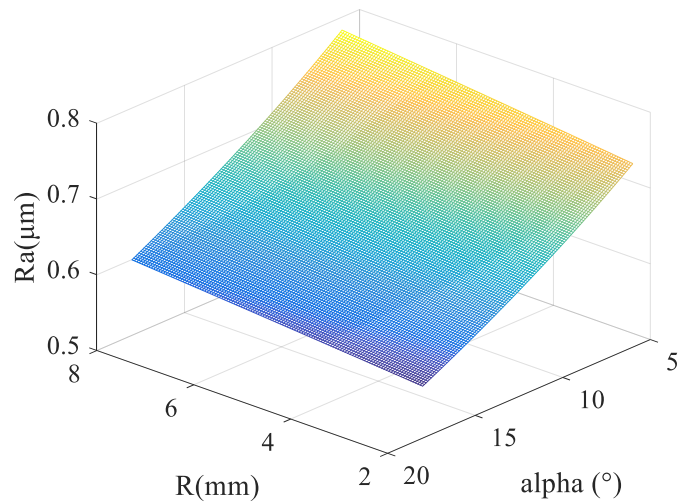

(a) Influence of $R$ and $\alpha$ on $R_{a}$

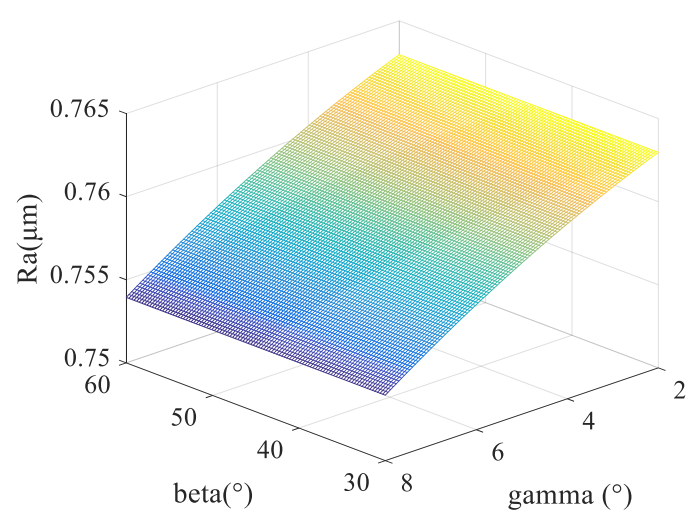

(c) Influence of $\beta$ and $\gamma$ on $R_{a}$

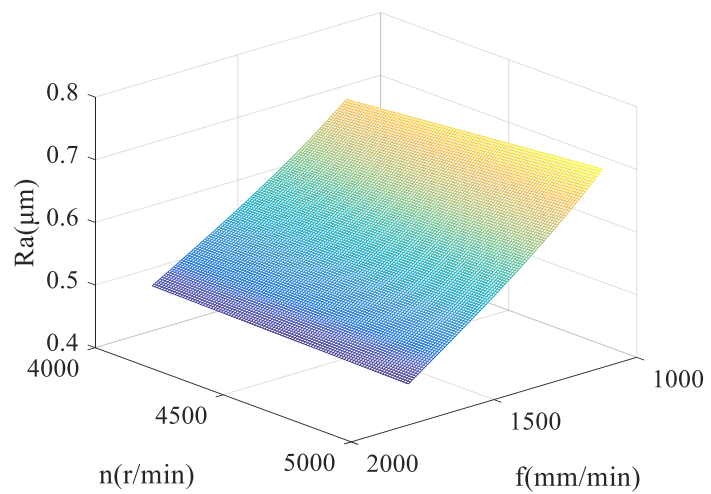

(e) Influence of $n$ and $f$ on $R_{a}$

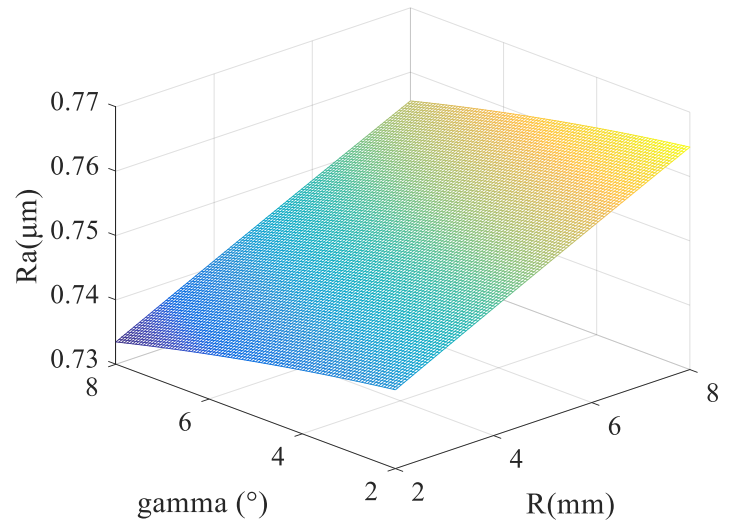

(b) Influence of $\gamma$ and $R$ on $R_{a}$

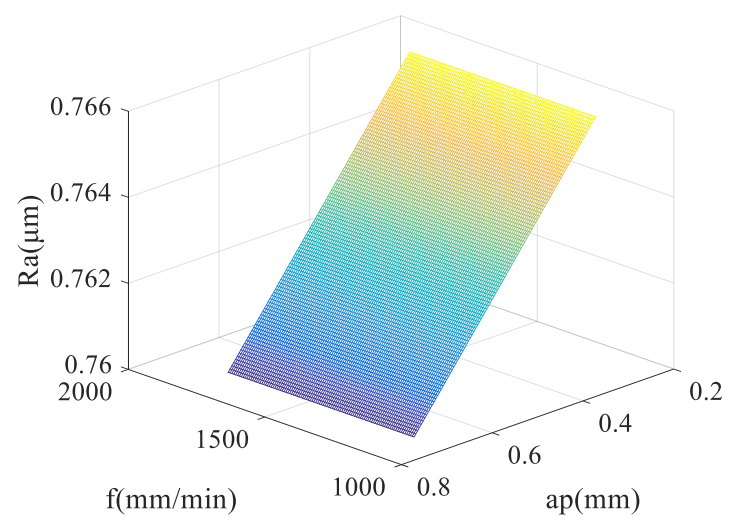

(d) Influence of $f$ and $a_{p}$ on $R_{a}$

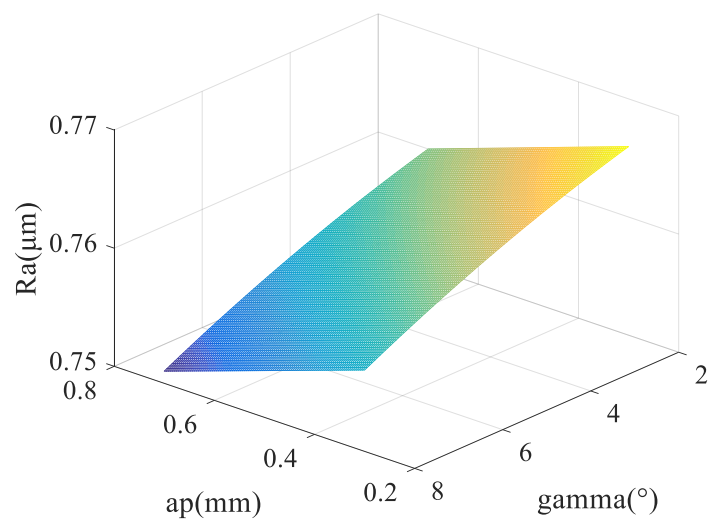

(f) Influence of $a_{p}$ and $\gamma$ on $R_{a}$

Figure 15. Cont. 


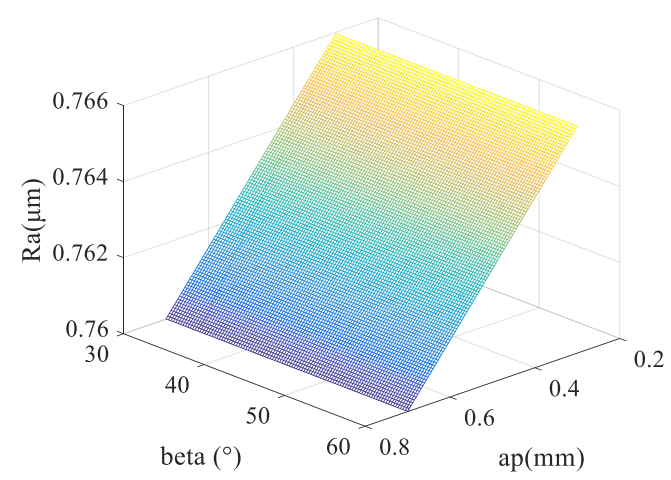

(g) Influence of $\beta$ and $a_{p}$ on $R_{a}$

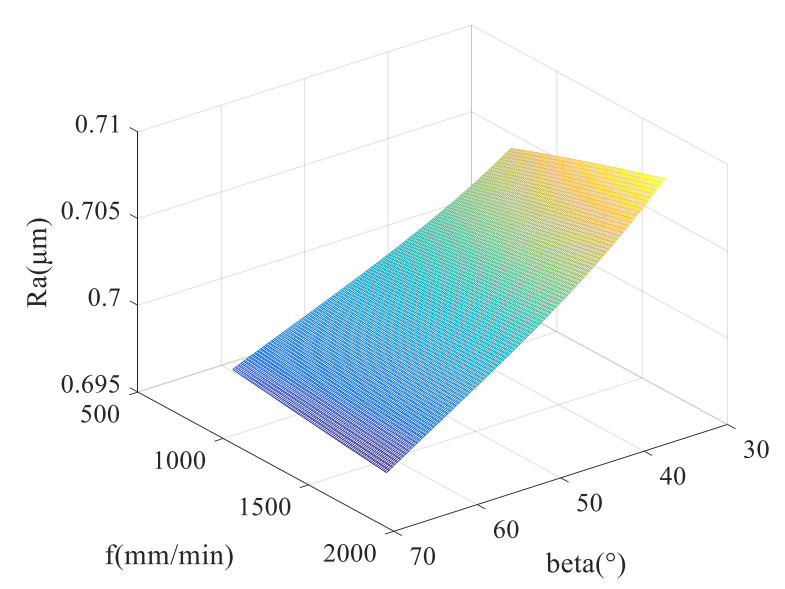

(h) Influence of $f$ and $\beta$ on $R_{a}$

Figure 15. Cross-factor analysis for $R_{a}$.

As shown in Figure 15a, the effect of $\alpha$ on $R_{a}$ is more significant than that of $R$. $R_{a}$ positively correlates with $R$, but negatively correlates with $\alpha$. Thus, to ensure the quality of the processing, unless there is a specific demand, when designing the tool parameters, it is inadvisable to design the tool with a small $\alpha$ value and large $R$ value. A similar situation also occurs in the effects of $\gamma$ and $R$ on $R_{a}$, as shown in Figure 15b. From Figure 15a,b, it can be seen that the effect of $R$ on $R_{a}$ is almost linear. However, the effect of $\alpha$ on $R_{a}$ appears as a concave function, and the effect of $\gamma$ on $R_{a}$ appears as an upper convex function, as shown in Figure 15c, comparing the cross factors $\gamma$ and $\beta, \beta$ has almost no effect on $R_{a}$. However, this is relative, as shown in Figure 15f; when $f$ is compared with $\beta, \beta$ has a greater effect on $R_{a}$, and as shown in Figure 15c, if the two factors $\beta$ and $\gamma$ present a great influential difference on $R_{a}$, the main design or selection object of the tool is $\gamma$ when the consistency of the tool during processing is insufficient, while $\beta$ with a relatively weak influence can be selected according to other influencing factors. A similar situation also occurs in the effects of $\gamma$ and $R$ on $R_{a}$, as shown in Figure 15d,e,g.

It is worth further regarding Figure 15f,h. In Figure 15f, both $a_{p}$ and $\gamma$ negatively correlate with $R_{a}$, the two factors under this interactive relationship should not be too small simultaneously because the change in the same direction of the two will result in a bigger change rate of $R_{a}$, but this may also be affected by their respective ranges of variation. In Figure 15h, the surface distortion as $\beta$ decreases indicates that the effect of $f$ on $R_{a}$ is not monotonous, but changes from a negative correlation to a positive correlation as $\beta$ increases, indicating there is a certain value of $\beta$ that lessens the effect of $f$ to almost none on $R_{a}$, and $\beta$ has a weakening or enhancing effect on the influence of $f$ on $R_{a}$. This weakening or enhancing effect can be used to balance the design during tool design or optimization. Furthermore, this conclusion is based on fixed conditions. Specific conditions may lead to conclusions that are inconsistent with experience and are not representative of actual results. Consequently, the influence level should be quantified in a way that considers the input conditions.

It is well known that the determination method of the objective function weight in the optimization algorithm has not been rigorously defined. There is no uniform solution outlined in academia studies, and there is no reliable solution in the field of tool performance design and optimization. However, the influence level of the factors can be quantified based on the analytical model, which can be used as a reliable basis for weight determination 


\section{General Method of Performance Design Based on the Analytical Model}

\subsection{Theoretical Flowchart}

Based on the above conclusions, the general method of performance design can be concluded as shown in Figure 16. After inputting the processing conditions, tool geometry parameters, and processing time, $d V B / d t$ and $R_{a}$ can be obtained, where $R_{a}$ is used as the performance index of the tool design. By defining the tool milling quality life failure criterion, the tool geometry can be designed with appropriate algorithms. At the same time, the machining time required can be obtained and the tool life prediction can be realized. Through substitution of the measured $V B$, the remaining tool life can be predicted for the worn tool. As tool wear increases, the tool geometry will change significantly. It is necessary to continuously correct the tool geometry parameters and coefficients in the model through the measurement data to ensure accuracy of the prediction and design.

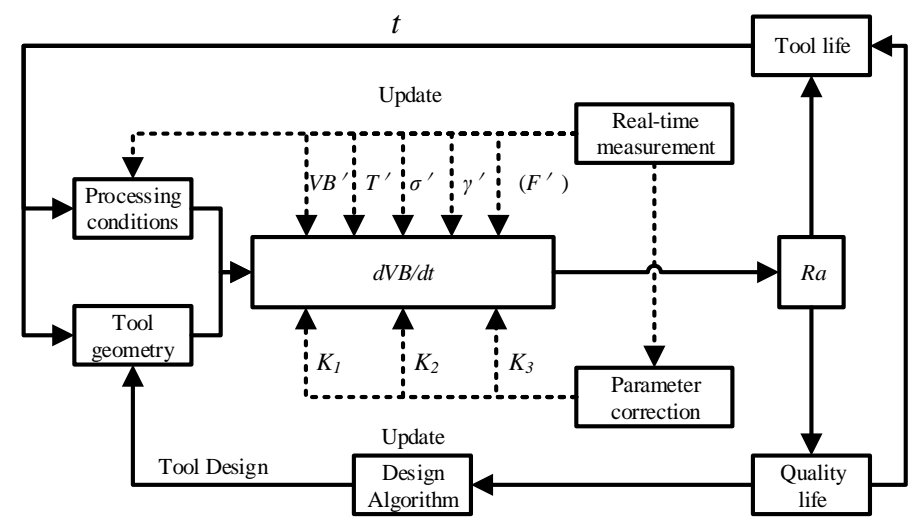

Figure 16. General method of performance design based on the analytical model.

\subsection{Application and Development}

Based on the above study, if the tool milling quality lifetime is set to ensure that the maximum surface roughness $R_{a}$ does not exceed $0.8 \mu \mathrm{m}$ and the continuous processing time of the tool is greater than $10 \mathrm{~h}$, then the genetic algorithm (GA), along with the objective function of Formula (9), can be utilized to convert these tool requirements into the design and milling parameters of the tool, where $\gamma$, $\sigma, \beta, n, f$, and $a_{p}$ are considered optimization objects. The optimization of the GA, along with other parameters, was set as in '4 Experiment and verification,' as shown in Figure 17.

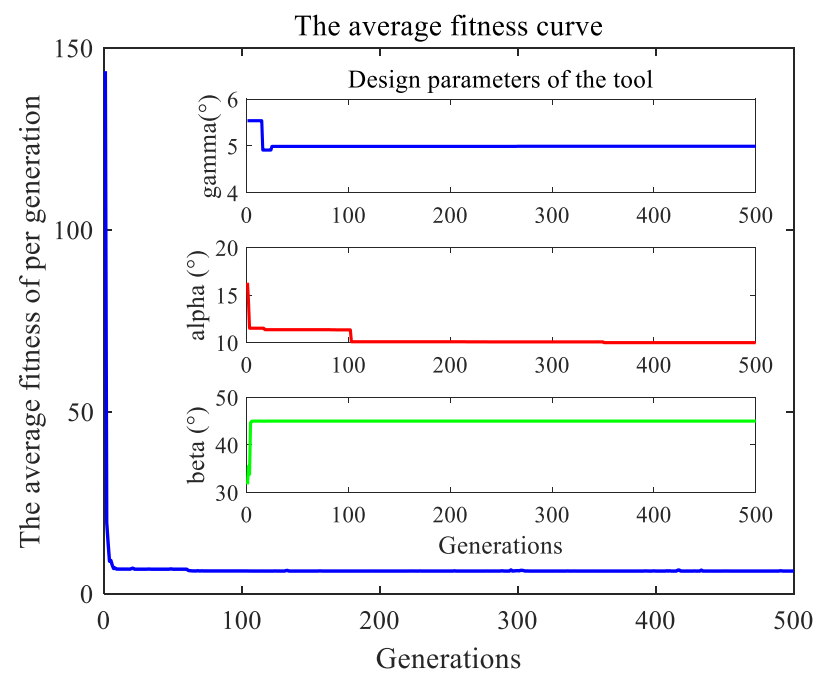

Figure 17. Cont. 


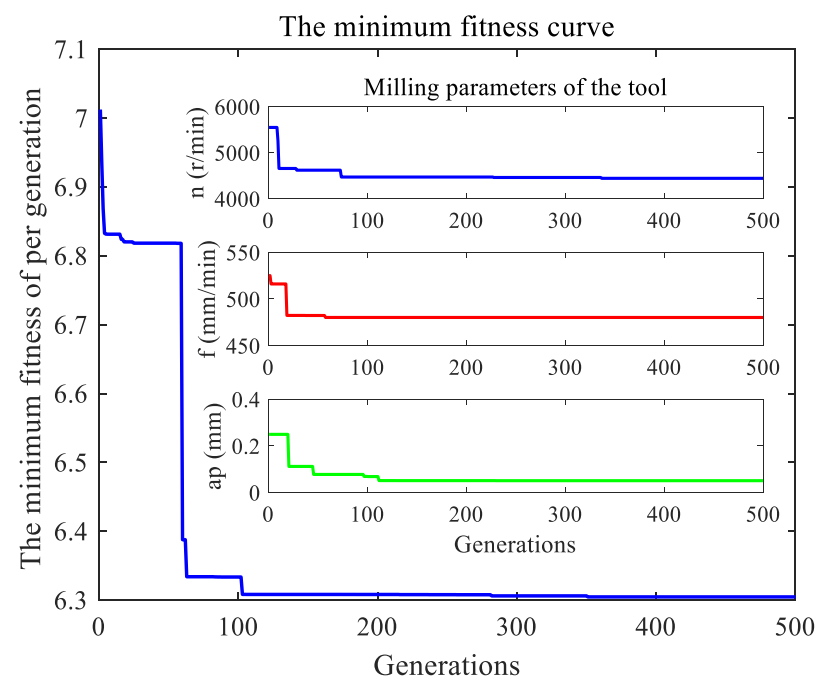

Figure 17. Genetic algorithm (GA) optimization process.

As shown in Table 5, the optimization results are not much different from the experimental parameters. It can be seen that only the depth of cut differs greatly from the experimental value. To obtain measurable wear as soon as possible during the experiment, milling depth $a_{p}$ was set to a series of larger values, whereas, the ideal value based on $R_{a}$ optimization should be approximately $0.064 \mathrm{~mm}$.

Table 5. GA optimization results.

\begin{tabular}{cccc}
\hline \multicolumn{2}{c}{ Tool Design Parameters } & \multicolumn{2}{c}{ Tool Milling Parameters } \\
\hline$\gamma\left({ }^{\circ}\right)$ & 5 & $n(\mathrm{r} / \mathrm{min})$ & 4083.6 \\
$\alpha\left(^{\circ}\right)$ & 10 & $f(\mathrm{~mm} / \mathrm{min})$ & 482.2 \\
$\beta\left(^{\circ}\right)$ & 45.8 & $a_{p}(\mathrm{~mm})$ & 0.064 \\
\hline
\end{tabular}

When the model is applied to other materials or milling tools, the 'tool geometry' shown in Figure 16 should be remodeled to express the different geometry characteristics. Additionally, the material parameters of the tool and workpiece should be replaced, as included in $K_{1}, K_{2}$, and $K_{3}$. However, the structure and material effects of the coating were not considered in this study, hence, should be evaluated using a different method in future studies.

\section{Conclusions}

In this paper, the geometric relation between the milling tool geometry, milling conditions, and milling tool performance was established and verified. The following conclusions can be drawn.

1. Among the many influencing factors, $R_{a}, \alpha, R, \gamma, a_{p}$, and $\beta$ are relatively significant, compared with the other factors, the influence of $f$ and $n$ were not as significant in this study, however, this may be affected by their respective ranges of variation. These important factors should be prioritized in the design and use of a tool to ensure consistency of the processing quality.

2. In many influential relationships, some factors either weaken or enhance the other, and the interaction characteristics of such factors should be utilized to balance the design during tool design or optimization.

3. Attention should be paid to the simultaneous changes of a certain couple of factors during the tool design or optimization process as a higher change rate of $R_{a}$ may occur.

4. This research provides service performance quantification and a general method of cutting tool performance design. The method is shown to be feasible and can be used for tool performance design or optimization. 
5. The material property parameters of the surface roughness model and the time-varying wear model proved to change dynamically with the processing in the experiments.

6. The model was established without considering crushing, built-up edge, and the slowing effect of the compound formed by the chemical reaction on the flank surface. Additionally, during the simulation process, the variation of the formula coefficients under different milling temperatures and time periods was not considered and the change of the tool geometry was not corrected with time. These are the main error sources of the model and simulation results.

Future research will focus on a material time-varying parameter prediction based on an algorithm to achieve tool performance and intelligent design.

Author Contributions: Visualization, validation, formal analysis, writing—original draft preparation, review and editing, Z.Z.; Investigation, resources, project administration, funding acquisition, X.L.; supervision, C.Y.; R.L.; software, H.Z.; Methodology, S.L. All authors have read and agreed to the published version of the manuscript.

Funding: This research was funded by: [National Natural Science Foundation's international (region) cooperation and exchange project: The basis and application of intelligent cutting technology based on open CNC system] grant number [5171001055]. [National Ministry of Science and Technology. National key R \& D plan. Network collaborative manufacturing and smart factory special project: "Complex Tool Monitoring and Full Life Cycle Intelligent Management and Control Technology"] grant number [2019YFB1704800]. [National Natural Science Foundation of China (Youth Fund) Research on the Stability of Five-Axis Machining of Double-Turn Table with Weak Rigidity Thin walled Parts] grant number [51905137]. And The APC was funded by [5171001055].

Conflicts of Interest: We declare that we have no financial and personal relationships with other people or organizations that can inappropriately influence our work, there is no professional or other personal interest of any nature or kind in any product, service and/or company that could be construed as influencing the position presented in, or the review of.

\section{Abbreviations}

$T$

$Q$

$t$

$D_{\text {min }}$

$R_{a}$

$R$

$Z_{0}$

$\gamma$

$\alpha$

$\beta$

$n$

$V_{c}$

$a_{p}$

$a_{w}$

$f$

$f_{z}$

$p$

$P_{\text {initial }}$

$\rho$

$\rho^{\prime}$

$\theta$

$\varphi$

$\omega$

$R_{o}$

$R_{M}$

$l_{M}$

h
Tool life

Quality life

Machining time

Minimum processing demand

Surface roughness

Ball radius

Number of teeth

Rake angle

Flank angle

Helix angle

Spindle speed

Milling speed

Milling depth

Milling width

Feed rate

Feed per tooth

Line spacing

Initial line spacing value

Curvature (vertical to feed)

Curvature (along feed)

Tool inclination angle

Equivalent angle

Final equivalent angle

Center distance

Radius at maximum wear

Depth at maximum wear

Residual height 
l

$T_{0}$

F

$\bar{\sigma}$

$\Delta R$

$\Delta V$

$V B$

$K_{1}, K_{2}, K_{3}$

$K_{0}, C_{0}$,

$a, b, c, d, g, e, n_{0}$
Wear band length

Milling temperature

Milling force

Average contact stress

Radial wear

Wear column

Maximum flank wear

Comprehensive wear coefficient

Model correction factor

Wear model parameters

\section{References}

1. Abele, E.; Hasenfratz, C.; Bucker, M. Modeling of process forces with respect to technology parameters and tool wear in milling Ti6Al4V. J. Prod. Eng. 2017, 11, 285-294. [CrossRef]

2. Yue, C.; Gao, H.; Liu, X.; Liang, S.Y. Part functionality alterations induced by changes of surface integrity in metal milling process: A review. Appl. Sci. 2018, 8, 2550. [CrossRef]

3. Ji, W.; Zhao, Z.; Liu, X. A GA-based optimization algorithm for cutting tool "shape-performance-application" integrated design approach. Proced. CIRP 2016, 56, 90-94. [CrossRef]

4. Ji, W.; Zhao, Z.; Liu, X. Tool shape-performance-application integrated design approach: A development and a numerical validation. Int. J. Adv. Manuf. Technol. 2017, 94, 1-7. [CrossRef]

5. Liu, X.; Ji, W.; Fan, M.; Wang, C. Feature based cutting tool "shape-performance-application" integrating design approach. J. Mech. Eng. 2016, 52, 146-153. [CrossRef]

6. Khan, M.R. Geometric modeling, design, and analysis of custom-engineered milling cutters. Jabalpur 2011, 2, 543-550.

7. Huang, Y.; Liang, S.Y. Modeling of CBN tool flank wear progression in finish hard turning. J. Manuf. Sci. Eng. 2004, 126, 98-106. [CrossRef]

8. Li, K.M.; Liang, S.Y. Flank wear model for near dry turning under built-up edge effect. Chin. J. Mech. Eng. 2012, 33, 123-132.

9. Teitenberg, T.M.; Bayoumi, A.E.; Yucesan, G. Tool wear modeling through an analytic mechanistic model of milling processes. Wear 1992, 154, 287-304. [CrossRef]

10. Bouzakis, K.D.; Paraskevopoulou, R.; Katirtzoglou, G. Predictive model of tool wear in milling with coated tools integrated into a CAM system. CIRP Ann. Manuf. Technol. 2013, 62, 71-74. [CrossRef]

11. Zhao, Z.; Liu, X.; Yue, C. Time-varying analytical model of ball-end milling tool wear in surface milling. Int. J. Adv. Manuf. Technol. 2020, 1-15. [CrossRef]

12. Biondani, G.B. Effect of cutting edge micro geometry on surface generation in ball end milling. CIRP Ann. 2019, 68, 571-574. [CrossRef]

13. Kasim, M.S.; Hafiz, M.S.A. Investigation of surface topology in ball nose end milling process of Inconel 718 . Wear Part. B 2019, 426-427, 1318-1326. [CrossRef]

14. Ghoreishi, R.; Roohi, A.H.; Ghadikolaei, A.D. Evaluation of tool wear in high-speed face milling of $\mathrm{Al} / \mathrm{SiC}$ metal matrix composites. J. Braz. Soc. Mech. Sci. Eng. 2019, 41, 146. [CrossRef]

15. Cagrı, V.; Turgay, K.; Murat, S.; Senol, S. Evaluation of tool wear, surface roughness/topography and chip morphology when machining of Ni-based alloy 625 under MQL, cryogenic cooling and CryoMQL. J. Mater. Res. Technol. 2020, 9, 2079-2092.

16. Reza, G.; Roohi, A.H.; Amir, D.G. Analysis of the influence of cutting parameters on surface roughness and cutting forces in high speed face milling of Al/SiC MMC. Mater. Res. Express 2018, 5, 56-73.

17. Wojciechowski, S.; Twardowski, P. Tool life and process dynamics in high speed ball end milling of hardened steel. Proced. CIRP 2012, 1, 289-294. [CrossRef]

18. Ahmad, F.; Gu, L.; Zhao, W.; Rajurkar, K.P. Tool path optimization based on wear prediction in electric arc sweep machining. J. Manuf. Processes 2020, 54, 328-336.

19. De Aguiar, M.M.; Diniz, A.E.; Pederiva, R. Correlating surface roughness, tool wear and tool vibration in the milling process of hardened steel using long slender tools. Int. J. Mach. Tools Manuf. 2013, 68, 1-10. [CrossRef] 
20. Bouzakis, K.-D.; Aichouh, P.; Efstathiou, K. Determination of the chip geometry, cutting force and roughness in free form surfaces finishing milling, with ball end tools. Int. J. Mach. Tools Manuf. 2003, 43, 499-514. [CrossRef]

21. Grzesik, W. Influence of tool wear on surface roughness in hard turning using differently shaped ceramic tools. Wear 2008, 265, 327-335. [CrossRef]

22. Zhang, C.; Zhang, H.; Li, Y. Modelling and on-line simulation of surface topography considering tool wear in multi-axis milling process. Int. J. Adv. Manuf. Technol. 2015, 77, 735-749. [CrossRef]

23. Tunc, L.T. Smart tool path generation for 5-axis ball-end milling of sculptured surfaces using process models. Robot. Comput. Integr. Manuf. 2019, 56, 212-221. [CrossRef]

24. Wang, X.; Feng, C.X. Development of empirical models for surface roughness prediction in finish turning. Int. J. Adv. Manuf. Technol. 2002, 20, 348-356. [CrossRef]

25. Mansour, A.; Abdalla, H. Surface roughness model for end milling: A semi-free cutting carbon casehardening steel (EN32) in dry condition. J. Mater. Process. Technol. 2002, 124, 183-191. [CrossRef]

26. Lee, K.Y.; Kang, M.C.; Jeong, Y.H. Simulation of surface roughness and profile in high-speed end milling. J. Mater. Process. Technol. 2001, 113, 410-415. [CrossRef]

27. Davim, J.P. Book review: Tribology of metal cutting by Viktor, P. Astakhov. Int. J. Mach. Mach. Mater. 2009, 5, 367-368. [CrossRef]

28. Alauddin, M.; Baradie, M.A.E.; Hashmi, M.S.J. Prediction of tool life in end milling by response surface methodology. J. Mater. Process. Technol. 1997, 71, 456-465. [CrossRef]

29. Sun, H.; Wang, Z.; Zhang, Y. Evaluation method of product-Service performance. Int. J. Comput. Integr. Manuf. 2012, 25, 150-157. [CrossRef]

30. Urbikain, G.; de Lacalle, L.N.L. Modelling of surface roughness in inclined milling operations with circle-segment end mills. Simul. Model. Pract. Theory 2018, 84, 161-176. [CrossRef]

31. Eshi, U. Cutting and Grinding Processing; Mechanical Industry Press: Beijing, China, 1982; pp. 34-36.

32. Kan, N. Advances in stochastic theory of fatigue damage accumulation. Adv. Mech. Eng. 1999, 31, 43-65.

33. Su, Y.; He, N.; Li, L. An experimental investigation of effects of cooling/lubrication conditions on tool wear in high-speed end milling of Ti-6Al-4V. Wear 2006, 261, 760-766. [CrossRef]

34. Ezugwu, E.O.; Wang, Z.M. Titanium alloys and their machinability-A review. J. Mater. Proc. Technol. 1997, 68, 262-274. [CrossRef]

35. Sui, S.C.; Feng, P.F.; Mou, W.P. Temperature modeling analysis for milling of titanium alloy. Key Eng. Mater. 2016, 693, 928-935. [CrossRef]

36. Werner, J.; Andreas, K. Soil surface roughness measurement-Methods, applicability, and surface representation. Catena 2005, 64, 174-192.

37. Yue, C.; Gao, H.; Liu, X.; Ling, S.Y.; Wang, L. A review of chatter vibration research in milling. Chin. J. Aeronaut. 2019, 32, 1-28. [CrossRef]

38. Wojciechowski, S.; Mrozek, K. Mechanical and technological aspects of micro ball end milling with various tool inclinations. Int. J. Mech. Sci. 2017, 134, 424-435. [CrossRef]

(C) 2020 by the authors. Licensee MDPI, Basel, Switzerland. This article is an open access article distributed under the terms and conditions of the Creative Commons Attribution (CC BY) license (http://creativecommons.org/licenses/by/4.0/). 